\title{
Resistências trans no voleibol feminino paranaense
}

\author{
Rafael Marques Garcia ${ }^{1}$
}

Resumo: Este trabalho objetivou problematizar as resistências de mulheres transexuais no voleibol feminino do Estado do Paraná, tendo como questões norteadores: 1- de que forma essas atletas constroem redes de resistência para permanecerem no voleibol? 2quais barreiras irrompem como entraves ao longo de sua(s) trajetória(s) pessoal(is) e esportiva(s)? Metodologicamente, desenvolveu-se um estudo qualitativo, contando com dois depoimentos de duas atletas mulheres trans de voleibol, que atuam na região metropolitana de Curitiba/PR. Trataram-se os dados com base na técnica de análise de conteúdo. Os resultados apontaram para os processos de resiliência e manutenção no terreno esportivo, constantemente cerceado por elementos cisheteronormativos que, ao se imporem, silenciam as corporalidades trans. No entanto, as atletas contam com apoio de seus grupos sociais e persistem em sua trajetória, em meio a percalços que surgem tanto durante os jogos, como fora das quadras e em outras esferas, como na legislativa, por exemplo.

Palavras-chave: Pessoas transgênero; Mulheres; Esportes; Voleibol; Brasil.

\section{Introdução}

O voleibol é uma modalidade enigmática no universo do Esporte. Dentre as diversas práticas que se pode encontrar nesse fenômeno, a supracitada emerge como importante espaço de viabilização para corpos e performances dissonantes da heteronorma, isto é, corpos que escapam dos padrões inteligíveis entre sexo/gênero/desejo/performance (BRITO, 2018).

Neste cenário, não é difícil evidenciar o maior engajamento do público feminino, de homossexuais e demais membros da sigla LGBTI+ (lésbicas, gays, bissexuais, travestis, transexuais, transgêneros, intersexuais e mais) no voleibol. Várias competições

\footnotetext{
${ }^{1}$ Doutor em Educação Física pelo PPGEF/UFRJ. Universidade Federal do Rio de Janeiro. E-mail: rafa.mgarcia@hotmail.com
}

Vol. 03, N. 12, Out.-Dez., 2020 - http://periodicoscientificos.ufmt.br/ojs/index.php/rebeh/index 
intituladas como plurais às diversidades sexuais e de gênero já existem em território nacional, tais como o Grand Prix LGBT de Vôlei, realizada anualmente no Estado do Amazonas (BRITO, 2018); e o GayPrix de Vôlei, campeonato nacional LGBTI+ iniciado em 2018, em Porto Alegre/RS, que teve a segunda edição em 2019 no Rio de Janeiro/RJ e em 2022 terá sua terceira edição na cidade de Belo Horizonte/MG.

Notadamente, é também no voleibol que se observa uma maior quantidade de atletas transexuais, principalmente após a publicação das novas recomendações do Comitê Olímpico Internacional (COI), de 2015, para balizar a participação oficial de atletas trans e/ou intersexuais, e com hiperandrogenismo em competições (inter)nacionais. Casos como o da brasileira Tifanny Abreu, da italiana Alessia Ameri e da espanhola Omy Perdomo já foram alvo de problematizações midiáticas e científicas, sendo amplamente discutidas mundo afora pelos veículos de comunicação (ESPORTE ESPETACULAR, 2017; 2018; 2019a; 2019b).

Tifanny iniciou seu processo de transição na idade adulta e Omy o fez desde criança, desenvolvendo-se durante a puberdade já com as intervenções hormonais necessárias para sua feminização ${ }^{2}$. Já o caso de Alessia é emblemático: embora seja situada como trans pelos estudos de gênero e esporte, a atleta nasceu com a Síndrome de Morris, caracterizada pela incapacidade parcial ou total do corpo de responder aos hormônios andrógenos, incluindo a testosterona. Mesmo apresentando o par de cromossomos sexuais XY, Alessia não se desenvolveu sob influência desses hormônios, já que, na prática, mesmo produzindo-os endogenamente, eles não desempenharam sua função esperada ${ }^{3}$.

Neste estudo, em especial, tenho por objetivo problematizar as resistências ${ }^{4}$ de mulheres transexuais no voleibol feminino que atuam/atuaram no Estado do Paraná, tendo como questões norteadores as seguintes perguntas: 1- de que forma essas atletas

\footnotetext{
${ }^{2}$ Cf. https://globoesporte.globo.com/tenis/noticia/primeira-trans-a-jogar-na-espanha-afasta-comparacoescom-tifanny-somos-completamente-diferentes.ghtml

${ }^{3}$ Cf. https://oglobo.globo.com/esportes/na-italia-tifanny-ja-dividia-opinioes-nao-usava-vestiario-do-timefeminino-22415060

${ }^{4}$ Em tese de doutorado, constatei que a trajetória de atletas mulheres trans no voleibol carrega processos de adversidades múltiplas. Neste interim, assumo os processos de resistência como inerente às trajetórias dessas atletas, o que não quer dizer necessariamente que já condiciono os achados deste trabalho a esse desfecho frente às dificuldades por elas apresentadas.
}

Vol. 03, N. 12, Out.-Dez., 2020 - http://periodicoscientificos.ufmt.br/ojs/index.php/rebeh/index 


\section{贯织}

constroem redes de resistência para permanecerem no voleibol? 2- quais barreiras irrompem como entraves ao longo de sua(s) trajetória(s) pessoal(is) e esportiva(s)?

Ciente de que a transexualidade ainda é um fenômeno problemático ao Esporte moderno, já que não consegue ser absorvida sob à ótica estruturante cisgênera empregada a esta instituição em questão, este estudo se justifica por trazer à tona desfechos de resiliência e fixação da identificação transexual feminina no voleibol feminino brasileiro, contribuindo assim para desmistificar preconceitos iniciais sobre a temática e para promover novas reflexões acerca das práticas esportivas na atual contemporaneidade, onde os corpos não são apenas mais produzidos biologicamente, mas também modelados socioculturalmente através de técnicas e intervenções estéticas e/ou cirúrgicas (PRECIADO, 2014).

\section{Metodologia}

A presente pesquisa foi avaliada e aprovada pelo Comitê de Ética em Pesquisa do Hospital Universitário Clementino Fraga Filho da Universidade Federal do Rio de Janeiro - HUCFF/UFRJ -, sendo o $\mathrm{n}^{\mathrm{o}}$ do Protocolo: 098-19; $\mathrm{n}^{\mathbf{0}}$ do CAAE: 10289419.5.0000.5257; e $\mathrm{n}^{\mathrm{o}}$ do parecer: 3.387.888. Caracteriza-se como descritiva e de cunho qualitativo, isto é, almeja amplificar e discutir de forma crítica as problematizações pertinentes à luz do objetivo elencado nesta empreitada (TRIVIÑOS, 2015).

Para tanto, contatei cinco mulheres transexuais que são atletas de voleibol semiprofissional e/ou amador, e que atuam/atuaram no Estado do Paraná, através do aplicativo de rede social virtual Instagram. Com base em Murthy apud Jardim (2018), entende-se que a vida cotidiana é cada vez mais mediada pelas tecnologias modernas, onde o meio digital também passou a constituir o campo de pesquisas acadêmicas. Pink et al. (2015) nos ajudam a perceber como os universos digitais e reais, nos dias atuais, estão interligados de uma maneira forte, produzindo e remodelando relações de poder e de interdependência, ou seja, estão redefinindo as formas de produção acadêmica. "The openness", que é a ideia de um processo sem fim ou fechamento, é um evento aberto, que abre a perspectiva para a subjetividade dos desdobramentos de uma análise digital. Pink 


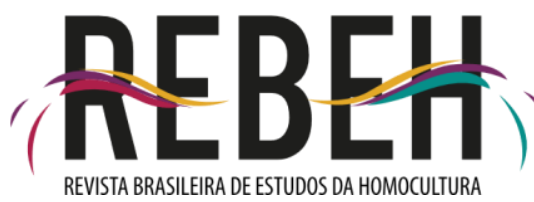

et al. (2015, p. 2) afirmam que "fazer pesquisas com, através de, e em um ambiente parcialmente constituído por mídia digital levou ao desenvolvimento de métodos novos e inovadores e desafiou os conceitos e categorias analíticas".

Sendo assim, o aplicativo Instagram surgiu como uma potencialidade para a realização da pesquisa, principalmente no que tange ao processo de coleta de dados. Ao contatar as cinco atletas, duas não responderam e uma disse não querer participar do estudo. Sendo assim, obtive respostas positivas de apenas duas atletas, MS e $\mathrm{PF}^{5}$, que concordaram em participar da pesquisa e ter seus dados aqui expostos, única e exclusivamente para fins acadêmicos.

O contato virtual ocorreu no dia 04 de maio de 2020, onde realizei uma entrevista aberta com MS e logo em seguida, com PF. As perguntas desenvolvidas foram fluindo de acordo com as respostas das entrevistadas e mantendo certo cuidado para não gerar qualquer constrangimento (para isso, foi garantido às atletas o direito de não responder qualquer pergunta que não quisessem). Ao final das entrevistas, todo material coletado foi exportado para o software Microsoft Word, onde puderam ser lidos, relidos, agrupados e interpretados ${ }^{6}$.

Para analisar o material, recorri à técnica de análise de conteúdo (BARDIN, 2016). A autora explica que essa técnica de análise é esquematizada a partir de três grandes ações, sendo a primeira delas a pré-análise, onde se faz uma leitura cuidadosa dos enunciados registrados, também chamada de leitura flutuante: aqui, alguns dados irão despontar-se no texto de acordo com o objetivo a ser investigado; na segunda etapa, denominada decodificação e categorização, os trechos mais significantes são comparados e através desse processo de recolhimento sistemático, agrupam-se esses dados em grandes categorias de análise; por fim, no terceiro momento, as interpretações textuais são

\footnotetext{
${ }^{5}$ Para preservar o anonimato, gravei apenas as iniciais dos nomes das entrevistadas.

${ }^{6}$ As conversas foram transportadas de forma literal. Por ter se desenvolvido em uma plataforma digital não formal, as falas foram descritas contendo abreviações e vícios da linguagem virtual. Neste documento, tomei a liberdade de corrigi-las segundo a norma padrão da Língua Portuguesa, sem, no entanto, mudar seu sentido e/ou significado. Destaca-se ainda que, terminada a redação deste documento, foi enviado às duas depoentes para que pudessem ratificar as interpretações aqui tecidas. Só então o texto foi finalizado e publicizado.
}

Vol. 03, N. 12, Out.-Dez., 2020 - http://periodicoscientificos.ufmt.br/ojs/index.php/rebeh/index 


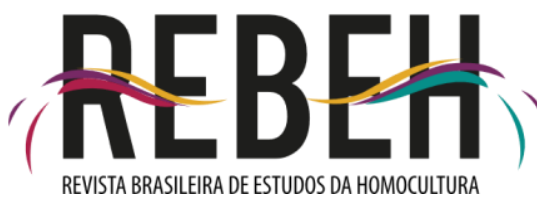

desenvolvidas à luz do arcabouço teórico básico selecionado para discutir os dados em questão.

Desta forma, foi possível agrupar a narrativa das atletas a partir das seguintes unidades: 1- a identificação transfeminina; 2- membros da instituição esportiva e; 3regulamentos oficiais. Em cada uma delas trago problematizações a partir do que foi evidenciado ao longo das entrevistas concedidas.

\section{Resultados e discussão}

\section{1- A identificação transfeminina}

MS reside em Pinhais, na região metropolitana de Curitiba. Começou a transicionar de gênero aos 21 anos. Faz uso de hormônios sem acompanhamento médico há 5 anos e hoje está com 29 anos, disputando competições masculinas e mistas enquanto aguarda a documentação com registro social. Já recebeu propostas de equipes femininas para atuar pelo Estado do Paraná. Tem $1,87 \mathrm{~m}$ e atua como ponteira. Atualmente, é profissional do sexo, porém afirma que assim que tiver sua documentação retificada, pretende tornar-se atleta profissional em uma equipe de voleibol feminino do respectivo Estado.

$\mathrm{PF}$ atua na equipe Paraná Clube, da cidade de Curitiba. Começou sua transição de gênero aos 15 anos, hoje tem 37, 1,83m de altura e atua como ponteira e/ou oposta. Desde o princípio fez uso de hormônios, primeiro por conta própria, depois passando a ser acompanhada medicamente. Casada há oito anos, PF conta com o apoio da família e do esposo, sendo atualmente estudante de Pedagogia. Assim como MS, almeja tornar-se atleta profissional da modalidade.

Ao longo de seu processo de transição, MS relata que o voleibol foi de suma importância em sua vida e que jogou em muitas equipes paranaenses ao longo de sua trajetória no naipe masculino: "Joguei todo meu tempo de menino pela seleção de Pinhais, vários campeonatos estaduais, muitas viagens pelo Paraná todo. Todo esse momento foi importante para mim, pois fazia o que eu gostava de fazer, que era jogar vôlei". Entretanto, atuar no masculino causava-lhe desconforto e constrangimento: "Mesmo 


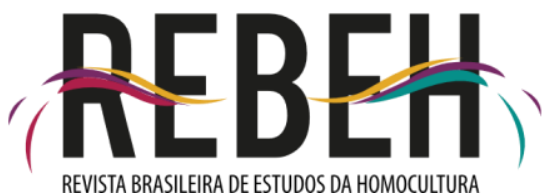

atuando como masculino, eu sentia que ali não era meu lugar por eu ser um gay muito afemininado, pelo jeito de eu jogar e me sentir bem jogando, meus técnicos no clube às vezes me criticavam por eu querer jogar como menina, trejeitos e tals [sic]".

Brito $(2016 ; 2017 ; 2018 ; 2019)$ problematiza a resistência acima descrita que é conferida aos atletas homossexuais que atuam de maneira diferente àquela de que se espera socialmente para um menino/homem. Muitas vezes, o fato de o atleta possuir uma corporalidade que escapa ao padrão cisnormativo é a justificativa velada que técnicos e treinadores escolhem para cortá-los, alegando que estão rendendo menos ou não estão jogando bem. Em outras ocasiões, entretanto, essa mesma peculiaridade pode ser acionada para instigar o desempenho do atleta, conforme foi destacado pelo autor em sua tese de doutoramento (BRITO, 2018).

MS, entretanto, seguiu firme no objetivo: "Mesmo assim fui seguindo ali, jogando vários campeonatos, meio quietinha, daquele jeito, por não poder me soltar [...] Joguei muitos e muitos campeonatos onde me destaquei, ganhando vários prêmios individuais. Peguei seleção paranaense duas vezes, joguei o Brasileiro em Saquarema, onde era meu grande sonho conhecer, foi um momento inesquecível para mim [...] Mas vi que ali no masculino não era onde eu me sentia bem, que sofria preconceito pelo meu jeito de jogar [...] Daí tomei a decisão de me transicionar, aos 21 anos. Mas fui começando aos poucos por conta da minha família".

A família neste contexto tem papel estrutural de apoio importante às pessoas que se reconhecem como transexuais, entretanto, conforme destaca Bomfim (2009), essa convivência pode ser conflituosa em função dessa nova identificação, o que muitas vezes leva as famílias a rejeitarem seus membros desta condição, sujeitando-os às situações precárias e de extrema vulnerabilidade socioeconômica. Embora MS tivesse certo receio no início, foi bem acolhida pelos membros familiares, assim como PF, que também contou com o apoio familiar desde sempre.

PF diz: "Sou acolhida e amada até hoje pela minha mãe e irmãs. Meus pais são separados e eu não tive um convívio sadio com meu pai, porque ele era alcóolatra [...] Agora tenho o marido e o sogro, me sinto bem feliz e apoiada por ambos os lados". Assim como MS, PF também iniciou sua intervenção hormonal por conta própria, já que, 


\section{员드탠}

segundo ela, não era abertamente declarada mulher trans para sua família: "Fazia por conta, pois não era assumida pra família”.

Conforme aponta Petry (2015), as pessoas que se identificam como mulheres transexuais recorrem ao processo de intervenção hormonal para promover mudanças físicas em sua estrutura corporal que as aproximarão da imagem feminina idealizada, tais como diminuição do crescimento de pelos faciais, redistribuição de gordura corporal, aumento dos seios, entre outros. Mesmos com os possíveis riscos desse procedimento, tais como "[...] trombose de veias profundas, alterações tromboembólicas, aumento da pressão arterial, alterações hepáticas e problemas ósseos" (PETRY, 2015, p. 73), percebese que "[...] experienciar sensações tidas como do escopo do feminino permitem [...] preencher os requisitos para se reconhecer - e se sentir reconhecida - como humana" (p. 73).

Desta forma, adotar a identificação transfeminina, que fixa a identificação de gênero como mulher, espelha-se nos moldes cisgêneros com o intuito de construir um visual passável, materializando assim a passabilidade de gênero que, em suma, traduz-se no reconhecimento social daquela pessoa como mulher, independente dos processos transexualizadores (JARDIM, 2018).

Se, por um lado, esse processo é extremamente benéfico para reconhecer e legitimar a identificação humana da pessoa e, portanto, seu direito à vida plena, por outro, torna-se desafiador por continuar fixando as identificações de gênero às normais cissexuais, conforme aponta Vergueiro (2015). Ao todo, o contrato com as artimanhas (hetero)normativas são estremecidas (PRECIADO, 2014), porém reformuladas a partir do que se entende por "ser mulher" na atual sociedade brasileira.

\section{2- Membros da instituição esportiva}

Nesta seção, considero como membros da instituição esportiva atletas, treinadores, gestores e também torcedores. Para ambas as entrevistadas, sua absorção pelos campeonatos que atuam é, em maioria, bem promovida, embora há de se destacar que MS ainda jogue entre homens, enquanto que PF já atua entre as mulheres cis. 


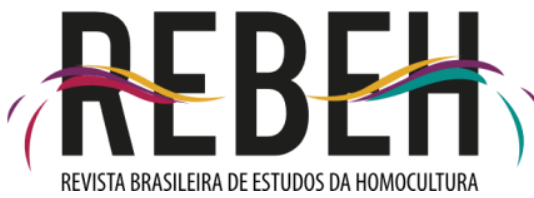

Para MS, já se tornou "normal” perceber reações quando está em quadra. Segundo a atleta, surgem comentários do tipo: “Já escutei algumas vezes 'uma mulher jogando com os homens?', agora um tipo de xingamento, assim não". PF denuncia que "Bom, todos olham a transição no esporte pelo lado Tifanny, mas eu, bem como a Maria Joaquina e a MS, começamos a transição na adolescência". Ao citar também o caso de MS, PF comenta: "Essa é uma comparação sensível, eu tô jogando legalizada, tudo certinho, no entanto, tem os comentários: 'ah lá um homem jogando', e a MS no meio dos homens 'ah lá uma mulher em quadra jogando'. A sociedade é tão hipócrita, até quando que eles vão ficar fazendo comparações desnecessárias ou irreais a respeito da gente? Eu acho que sabendo respeitar já basta, não precisa ficar comentando o que não sabe".

Sobre essa questão, Castro, Garcia e Pereira (2020) ratificam que essa é uma comparação indevida que se faz sobre as atletas trans que estão atuando nas modalidades esportivas. Se a atleta for uma mulher trans, tornou-se comum encontrar relatos de que há um homem em meio às mulheres (se ela estiver atuando no feminino), ou uma mulher em meio aos homens (se ela estiver atuando no masculino). Ou seja, existe uma contradição inerente ao fenômeno que, conforme pontuam Prado e Nogueira (2018), é um exercício transfóbico que visa deslegitimar a condição trans no Esporte, já que não se reconhece a identificação da mulher trans quando esta disputa competições femininas, porém o fazem quando ela está disputando competições masculinas. Em suma, essa (des)identificação contraditória nada mais seria que uma estratégia para excluir a identificação trans à luz das normas cisheteronormativas sociais embutidas no Esporte.

PF estende sua fala sobre tal à torcida, e diz que já recebeu, inclusive, ameaças: “Fui vaiada e ameaçada". Neste sentido, Wagner Camargo (2017, p. 1) problematiza o papel da torcida e suas ações: “[...] o que significa 'ser livre' para torcer? O que é estar em situação 'democrática' para torcer?”. A partir daí, reflete-se sobre até que ponto vai o papel do/a expectador/a neste cenário: à luz do autor, torcer é um artefato político, que reconhece no outro e a partir do outro as diferenças, buscando neste processo estabelecer hierarquias com base em preceitos diretos e antagônicos, uma herança que se herda do colonialismo (VERGUEIRO, 2015). 


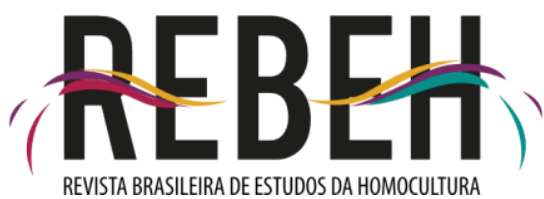

Para amplificar essa leitura, Prado e Nogueira (2018, p. 66) explicam que “[...] poucos são os códigos corporais valorizados e compreendidos como 'normais' em nosso contexto". Quando estendidas para as pessoas transexuais, "tais normativas produzem o rechaço, aversão e não reconhecimento social e jurídico de alguns sujeitos" (PRADO; NOGUEIRA, 2018, p. 66), o que faz do Esporte um espaço hostil para a inserção, permanência e reconhecimento das potencializações transexualizadoras dos corpos.

Prado e Nogueira (2018) explicam que o estranhamento é causado pelo entendimento calcado nas Ciências Biológicas que vêm, deste o século XVII, fixando e delimitando padrões ditos normais para corpos humanos através de suas instâncias do saber/poder, como a medicina, por exemplo (LE BRETON, 2014). A partir desse acionamento, todo e qualquer corpo que se apresente como transfeminino no voleibol, é rapidamente comparado aos casos mais notórios, tais como o da atleta Tifanny Abreu ${ }^{7}$.

Porém, PF bem lembra que nem todas as atletas fazem/fizeram sua transição após a fase adulta, tal qual Tifanny, citando dois casos nacionalmente conhecidos: o da jovem patinadora Maria Joaquina, que desde os dez anos faz acompanhamento médico tendo em vista seu processo transexualizador, e o de Isabelle Neres ${ }^{8}$, a primeira atleta trans a atuar no voleibol brasileiro feminino semiprofissional do Brasil, em 2017, tendo recebido autorização da Federação Paranaense de Voleibol, que consultou a Confederação Brasileira de Voleibol (CBV) para dirimir sobre a solicitação da atleta.

Os casos de MS e PF, todavia, reformulam as quadras do voleibol. Pela persistência e resistência das mesmas em continuarem atuando, passaram a ser (re)conhecidas pelo Estado paranaense, o que foi, aos poucos, sendo absorvido pela instituição esportiva da região de modo gradual e constante: com o tempo, esses processos de estranhamento, não reconhecimento e não pertencimento foram se esvaindo das atitudes dos atores/atrizes sociais coadjuvantes destes processos. MS diz: "Sou bastante conhecida já", e PF complementa: "Mas depois de um tempo, muitos me conhecendo

\footnotetext{
${ }^{7}$ Para mais informações sobre o caso da atleta, vide Prado e Nogueira (2018).

${ }^{8}$ A atleta foi uma das cinco contatadas do estudo, porém disse não estar mais concedendo seus depoimentos para estes fins. Para mais informações sobre o caso de Isabelle, recomenda-se visitar reportagem do canal esportivo SPORTV (2017), disponível em < http://sportv.globo.com/site/programas/sportvnews/noticia/2017/03/primeira-transgenero-jogar-volei-no-brasil-comemora-feito-muito-feliz.html $>$. Acesso em 11 mai. 2020.
}

Vol. 03, N. 12, Out.-Dez., 2020 - http://periodicoscientificos.ufmt.br/ojs/index.php/rebeh/index 


\section{员드댄}

vêm até mim se desculpar, e acabo ganhando amizades. Noto que falta informações à população sobre uma pessoa trans, somos vistas como estranhas, coisas ou objetos. Até que nos conheçam ou provamos que só estamos ali pra ter nosso espaço, mais nada [...] Triste realidade essa nossa!".

O desconhecimento da realidade trans, conforme destacado por PF, é uma potente arma de exclusão que se encontra disseminada na esfera esportiva (PRADO; NOGUEIRA, 2018), já que silencia as corporalidades que desviam das normativas cistêmicas esportivas, legitimando, portanto, a ideia do apagamento e silenciamento de corpos transgressores e alheios a tal (JARDIM, 2018).

Este processo, inclusive, vem sendo alimentado por deputados nas Assembleias Legislativas nacionais. Conforme matéria ${ }^{9}$ divulgada pelo Portal Online da Câmara dos Deputados do Brasil em 2019 (s/p), ao menos "Em doze Estados, as assembleias legislativas também estão examinando projetos de lei que tratam da participação de atletas transgênero em competições esportivas". Todas possuem em comum estabelecer como único critério o sexo biológico dos/as atletas para que possam competir.

Sobre mais esse desdobramento cistêmico de exclusão das corporalidades trans pelo/no espaço que são seus por direito, PF diz: "Cada um pensa o que quiser... Eu estou apta e não é minha genitália que me define! Ainda não sou operada, mas há tempos que me vejo mulher. Indiferente de qualquer julgamento ou 'pré-conceitos', ou ainda, 'conceitos formados"'. MS ratifica: "Leio bastante sobre o assunto. Acho que são pessoas que não sabem de nada, falam por falar sem saber ou procurar, sabe... Não sabem o que passamos, hormônios femininos por uma parte é bom, por outra ruim.... Nos deixam super lindas, femininas, na parte boa... Pela ruim, ficamos fracas, indisposta, às vezes não queremos ver a cara de ninguém, enjoadas, passamos até mal”.

Nesta passagem, MS evidencia um contraponto da intervenção hormonal: se por um lado esse processo faz com que se aproximem das características visuais tidas como femininas, por outro traz consigo efeitos indesejados que podem ser atenuados, mas não totalmente extirpados. No que tange aos possíveis impactos da hormonização no campo

\footnotetext{
9 "Para especialistas, ciência ainda não provou vantagem de atletas trans". Disponível em: < https://www.camara.leg.br/noticias/560808-para-especialistas-ciencia-ainda-nao-provou-vantagem-deatletas-trans/ >. Acesso em 07 mai, 2020.
}

Vol. 03, N. 12, Out.-Dez., 2020 - http://periodicoscientificos.ufmt.br/ojs/index.php/rebeh/index 
psicossocial, Hembree et al. (2017) destacam que o acompanhamento médico é de suma e vital importância para averiguar continuadamente as mudanças da/na saúde mental e do convívio social (amigos, família, emprego, sociedade, a vida de modo geral), já que, em termos relativos, as pessoas transexuais estão mais suscetíveis à violências físicas e simbólicas que, mesmo em condições de não hormonização cruzada, já podem desencadear episódios emocionais, tais como ansiedade e depressão, por exemplo, e que podem se intensificar (ou até mesmo surgir) durante/a partir (d)o tratamento (HEMBREE et al., 2017).

Os possíveis demais riscos físicos do processo de hormonização supracitado, para além das questões emocionais, encontram-se dispostos na figura a seguir:

Figura 1- Riscos médicos associados ao processo de hormonização ${ }^{10}$

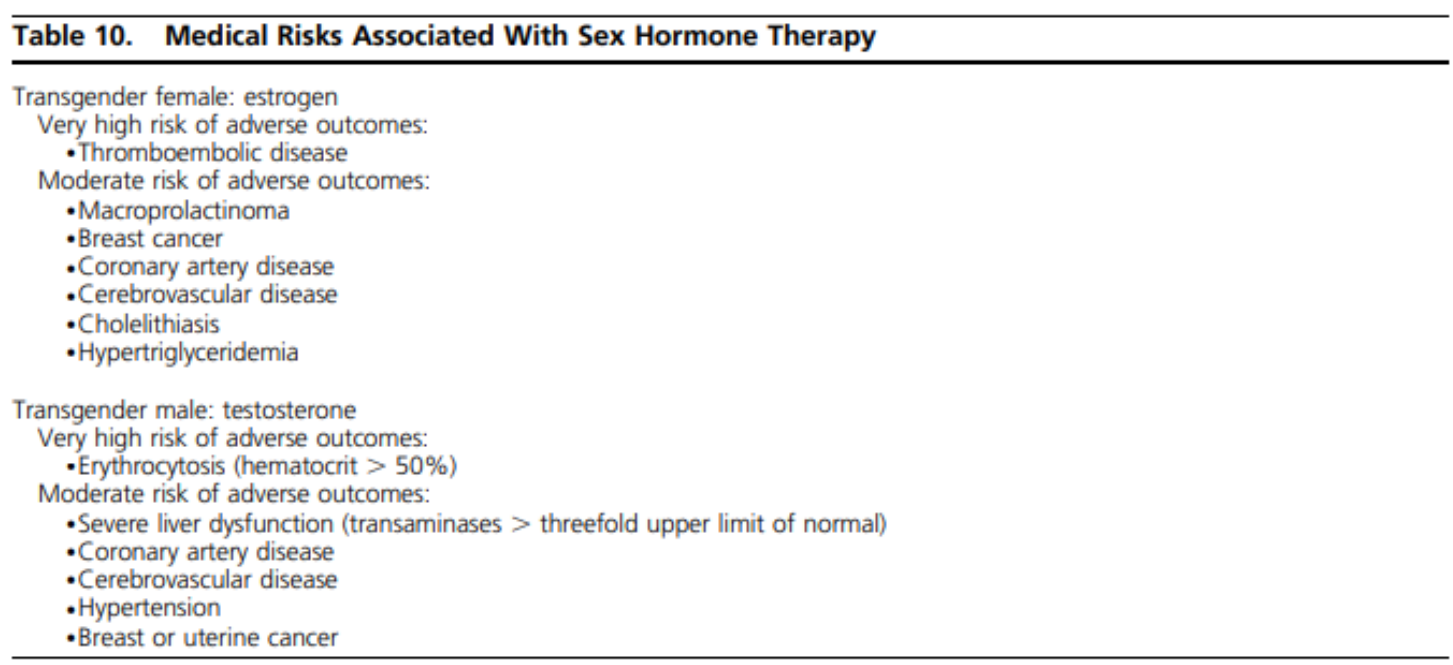

Fonte: Hembree et al. (2017)

\section{3- Regulamentos oficiais}

\footnotetext{
${ }^{10}$ Preferi manter a formatação no idioma original, registrando aqui sua tradução:

Mulher trans: estrogênio

Risco muito alto de resultados adversos: doença tromboembólica.

Risco moderado de resultados adversos: macroprolactinoma; câncer de mama; doença arterial coronariana; doença cerebrovascular; colelitíase; hipertrigliceridemia.

Homem trans: testosterona

Risco muito alto de resultados adversos: eritrocitose (hematócrito $>50 \%$ ).

Risco moderado de resultados adversos: disfunção hepática grave (transaminases > limite superior ao triplo do normal); doença arterial coronariana; doença cerebrovascular; hipertensão; câncer de mama ou uterino.
} 


\section{REBE员}

Nesta unidade, discute-se sobre a maneira como os regulamentos das competições lidam com a participação das atletas transexuais. Como já exposto, MS ainda atua em equipes masculinas, no máximo em equipes mistas, pois sua documentação ainda não está retificada. Ela iria recebê-la ainda em março de 2020, porém em decorrência da pandemia do novo Corona-Vírus, o que obrigou o Brasil a decretar estado de calamidade nacional, os serviços de cartório ficaram suspensos e, assim, MS aguarda o final desse momento para ter em mãos sua nova certidão de nascimento com o registro do nome social, que já consta em sua identidade RG. Ela diz: "Eu não estou jogando ainda [pelo feminino], jogo aqui campeonatos daqui, mistos. Quando me liberaram pra jogar feminino [...] vai ser incrível, vou chorar muito kkk [sic], emoção [...] Só terminando minha certidão...".

Neste cenário, o maior empecilho para MS poder competir entre as mulheres na Superliga, como ela mesma denota, é a falta de sua certidão de nascimento retificada. Sobre a sua dosagem hormonal de testosterona (mecanismo pelo qual o COI regula a participação de atletas trans entre os/as cis), MS diz que: "Não fiz meus exames de testosterona ainda, mas se eu tiver ainda, deve ser bem pouco".

Já para PF, a situação é diferente. Seu caso tornou-se conhecido em 2019, quando foi proibida de participar pela equipe feminina de Paranaguá nos Jogos Abertos do Paraná pelo Instituto Paranaense de Ciência do Esporte (IPCE), responsável por gerir a competição. O IPCE foi contrário à participação, porém a atleta acionou seus advogados, entrou com um recurso, mostrou seus exames hormonais e conseguiu a autorização, mesmo que tardia (só passou a atuar a partir das fases finais do campeonato). A defesa alegou que "ela não poderia ser barrada por ter sido considerada apta pela Federação Paranaense de Vôlei e pela Confederação Brasileira de Vôlei a jogar nas competições no feminino".

Sobre o ocorrido, PF explica: "Mesmo com o laudo médico e judicial, a secretaria do Estado quis me barrar por não apresentar os exames consecutivos, coisa que nem a Federação Paranaense nos pedia. Levei a papelada toda e ainda assim dificultaram. Acionei os advogados e fomos pra cima. Ainda assim a luta não foi fácil. Vieram com 


\section{REBE员}

mil e uma desculpas, mas após entrar em contato com a CBV, e ter a resposta do meu registro, voltaram atrás... Sendo 'bonzinhos"”.

PF também explica que a equipe subiu para a série A sem sua participação: “[...] as meninas passaram para a [série] A sem a minha ajuda, porque eu não estava podendo jogar, eu aguardei a decisão e respeitei para não prejudicar equipe de Paranaguá, só que quando a gente subiu para $\mathrm{A}$, que eu pude jogar, a gente não teve nenhum resultado extraordinário, a gente não se sobressaiu porque eu estava em quadra, muito pelo contrário".

PF tece esse comentário em função das inúmeras especulações que sugerem uma vantagem de atletas mulheres trans sobre as cis em competições esportivas. Nestas suposições, Prado e Nogueira (2018) pontuam que estas argumentações se valem de um discurso que oculta a própria variabilidade fisiológica entre os/as atletas cis. Para tanto, instigam a reflexão:

[...] no que se refere a suas dimensões biológicas seriam todas iguais? Não possuiriam estatura, peso, capacidade de produção hormonal também distintas? Isso causaria vantagem entre elas? Também não apresentam variabilidade biofisiológica para a produção de testosterona? Desta forma, as discussões sobre a aceitação ou não [...] em quadra realmente se pautariam em evidências ou o real argumento se encontraria velado nas discussões? (PRADO; NOGUEIRA, 2018, p. 69).

Para sustentar seu ponto de vista, PF explica que em outras competições seu rendimento em nada influenciou no resultado da equipe: "Dos jogos em Toledo, na fase final, nós não tivemos uma vitória e jogamos contra equipes fortes, São José dos Pinhais, que é da Superliga B, jogamos contra outras cidades e a gente não teve nenhuma vantagem, porque falam que tendo um atleta trans em quadra tem vantagem, mas eu não vejo essa vantagem e ninguém que estava lá viu. Pegamos uma fortíssima equipe de Marechal Cândido Rondon, que é praticamente a seleção paranaense, jogamos contra o sub-19 delas e não ganhamos". Em síntese, ela gostaria de saber: "Eu queria entender onde que o povo fala que tá essa vantagem”. Cabe frisar que, cientificamente, não existe consenso se há ou não vantagens, dada a tamanha complexidade da discussão, que 
demanda inúmeras interconexões entre aspectos sociais, biológicos e culturais (HARPER, 2019; FISCHER; MCCLEAREN, 2020).

Também, PF critica a forma como as normas se impõem de maneiras diferentes entre atletas cis e trans, o que, para ela, "É mais uma estratégia para dificultar a participação de atletas trans dizendo que os níveis hormonais, embora estejam abaixo de 10 nmol, não podem oscilar. Onde está isso na diretriz do COI? Se até os corpos sem terapia hormonal oscilam sem tratamento, qual a condição que criaram para atletas trans? Por mais que me esforce não entendo, muito menos os endocrinologistas que me acompanham".

Para complementar, ainda explica: "Eu sempre realizo meus exames mensalmente, minha média de testosterona é $2 \mathrm{nmol}$, o COI pede abaixo de 10 . Se mudarem pra $5 \mathrm{nmol}$, ainda estou dentro e apta à prática do esporte. Mais que buscar meu direito nas quadras, é o de conseguir a afirmação de gênero, cirurgia que também não é realizada sem burocracia mesmo tendo todos os laudos... É uma sequência de lutas que nos fazem refletir mesmo se é isso que queremos, mas quer saber, isso me dá mais força e vontade de perseverar. Não irei desistir agora que já cheguei até aqui”.

As novas recomendações do COI sugerem que

1. Aqueles que transitam de feminino para masculino são elegíveis para competir na categoria masculina sem restrição;

2. Aquelas que transitam de masculino para feminino são elegíveis para competir na categoria feminina sob as seguintes condições:

2.1. A atleta declarou que sua identificação de gênero é feminina. A declaração não pode ser alterada, para fins esportivos, por um período mínimo de quatro anos;

2.2. A atleta deve demonstrar que seu nível total de testosterona está abaixo de $10 \mathrm{nmol} / \mathrm{L}$ de sangue por pelo menos 12 meses antes de sua primeira competição;

2.3. O nível total de testosterona da atleta deve permanecer abaixo de 10 $\mathrm{nmol} / \mathrm{L}$ de sangue durante todo o período de elegibilidade desejada para competir na categoria feminina;

2.4. A conformidade com essas condições pode ser monitorada por testes. Em caso de não conformidade, a elegibilidade da atleta para a competição feminina será suspensa por 12 meses (IOC, 2015, p. 2-3, tradução minha). 


\section{苜ᄃBE吕}

Atualmente, o COI estuda reduzir a quantidade de testosterona de 10 para 5 nmol/L de sangue ${ }^{11}$, à exemplo do que já adota a Federação Internacional de Atletismo (IAAF). Todavia, a entidade máxima do Esporte internacional parece não se atentar ao fato de que a testosterona não é o único elemento a conferir ganhos em desempenhos atléticos, o que, em outras palavras, apenas continua mascarando as normas cistêmicas e heteronormativas que estão entranhadas nas práticas esportivas e que continuam produzindo performances vigiadas e controladas à luz da corporação cisheteronormativa (JARDIM, 2018).

Em meio a todo esse cenário, PF desabafa: "Ser trans no Brasil é dar a cara a tapa constantemente [...] Percebo muitos 'ignorantes' falando o que não sabem ou se baseando em opiniões infundadas, sem ao menos sequer se dar ao trabalho de pesquisar ou entender... Afinal, julgar é mais fácil, não é mesmo? Percebo treinadores julgando e criticando, mas nos bastidores pedem se eu jogo pra eles. Ainda, percebo reações e provocações vindas de técnicos dizendo às suas atletas que vão jogar com um homem trans... Tamanha ignorância que não sabem nem que sou uma mulher trans...".

Em meio às resistências que as atletas trans promovem ao Esporte, em especial a partir do voleibol, MS deixa o recado: "Não desistam dos seus sonhos, ninguém sabe o que você passa ou o que passou, não deixem te julgar sem te conhecer, siga em frente e deixem falando sozinhos...". E PF sintetiza: "Nunca desistam!".

\section{Considerações finais}

A materialização de uma identificação trans no voleibol, e neste caso em específico, a transexualidade feminina, é enigmática e ao mesmo tempo desvelada. Mesmo a modalidade sendo mais permissível para atletas que divergem da cisheteronormatividade, a instituição "Esporte", enquanto fenômeno e instância social,

\footnotetext{
${ }^{11}$ Assim como destaca PF, não foi e encontrada qualquer evidência científica que respalde o porquê da delimitação deste número como parâmetro do COI. Aqui, interessa questionar: de que forma o Comitê concluiu que as taxas deveriam ser de até $10 \mathrm{nmol} / \mathrm{L}$ ? Ou em quais embasamentos se apoia para reduzi-la a 5? Essas justificativas ainda não estão claras às federações e demais membros da instituição esportiva.
}

Vol. 03, N. 12, Out.-Dez., 2020 - http://periodicoscientificos.ufmt.br/ojs/index.php/rebeh/index 


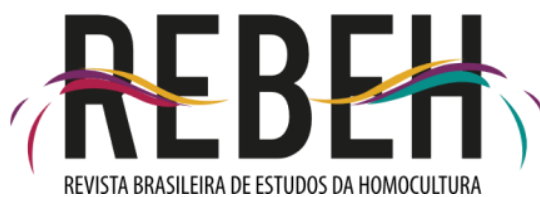

adota estratégias ainda muito resistentes às corporalidades que não se apresentam de forma inteligível entre sexo/gênero/corpo.

Pelo exposto, evidencia-se que tanto MS quanto PF enfrentam resistências significativas em seu processo de inserção e manutenção no voleibol feminino do Estado do Paraná. MS ainda luta para ter toda sua documentação e PF, que já apresenta todos os documentos retificados, ainda sofre com a vigilância e punição das esferas competentes, em função de argumentos biomédicos limitados ao funcionamento de um corpo cis.

A permanência de ambas no voleibol só é possível graças às redes de apoio que possuem, tanto no seio familiar quanto no trabalho e com demais membros da instituição esportiva. Não fosse a resiliência das atletas em driblar os comentários, os olhares, a repulsa e as constantes normatizações burocráticas que emergem como atoladores ao longo de suas trilhas esportivas, as mesmas dificilmente estariam competindo pela modalidade ou em qualquer outra que fosse.

A resistência traduz-se em luta e visibilidade, possibilitando que seus casos inspirem outras jogadoras e também que se passe a repensar os moldes competitivos na atualidade. Conforme já apontaram Prado e Nogueira (2018), os mecanismos competitivos de divisão pelo sexo biológico não conseguem mais dar conta da imensidão de diversidades corporais que se aventuram pelo Esporte na contemporaneidade. Embora o Esporte ainda seja um campo bastante problemático para processos transexualizadores, formas de ressignificá-lo e nele permanecer parecem inquietar as normas cisheteronormativas, ecoando o grito de resiliência, persistência e reconhecimento de mulheres transexuais entre as mulheres cis durante competições oficiais.

\section{Referências}

BARDIN, Laurence. Análise de conteúdo. Ed. rev. ampl. São Paulo: Edições 70, 2016.

BOMFIM, Patrick Thiago dos Santos. Discriminação e preconceito: identidade, cotidiano e religiosidade de travestis e transexuais. 2009. 132f. Dissertação (Mestrado em Psicologia). Universidade Católica de Brasília, Brasília/DF, 2009.

BRITO, Leandro Teófilo de. "Deixa a pinta pra fora da quadra": sobre heteronormatividade e precariedade no contexto do voleibol. In: SEMINÁRIO 
INTERNACIONAL ENLAÇANDO SEXUALIDADES, 1. 2017, Salvador/BA. Anais... Salvador/BA, $2017 . \quad$ Disponível em: https://www.editorarealize.com.br/revistas/enlacando/trabalhos/TRABALHO_EV072 MD1_SA18_ID268_19062017192331.pdf >. Acesso em 27 mar. 2020.

BRITO, Leandro Teófilo de. Enunciações de masculinidade em narrativas de jovens atletas de voleibol: leituras em horizonte queer. 225f. Tese (Doutorado em Educação). Faculdade de Educação da Universidade do Estado do Rio de Janeiro, Rio de Janeiro/RJ, 2018.

BRITO, Leandro Teófilo de. Identificações performativas do masculino no voleibol: narrativas de jovens adolescentes atletas em debate. Esporte e Sociedade, Niterói, v. 11, n. 28, p. 1-20, set. 2016.

BRITO, Leandro Teófilo de. Performances dissidentes no espaço do voleibol: masculinidades queer? In: PEREIRA, Erik Giuseppe Barbosa; SILVA, Alan Camargo (Orgs.). Educação Física, Esporte e Queer: Sexualidades em Movimento. Curitiba: Appris, 2019. p. 83-103.

CAMARGO, Wagner Xavier de. O torcedor queer. Lupopédio, São Paulo, v. 101, n. 26, p. 1-4, nov. 2017.

CASTRO, Pedro Henrique Zubcich Caiado de; GARCIA, Rafael Marques; PEREIRA, Erik Giuseppe Barbosa. O voleibol e a participação de atletas trans: outro ponto de vista. Motrivivência, Florianópolis, v. 32, n. 61, p. 01-22, abr. 2020.

ESPORTE ESPETACULAR. A atleta transexual Andraya Yearwood luta pelo direito de disputar provas no atletismo. 2019a. 27 de outubro de 2019. Disponível em: < https://globoplay.globo.com/v/8038455/ >. Acesso em 06 mai. 2020.

ESPORTE ESPETACULAR. Homens trans competem de igual para igual com outros homens. 2019b. 03 de novembro de 2019. Disponível em: < https://globoplay.globo.com/v/8056909/ >. Acesso em 06 mai. 2020.

ESPORTE ESPETACULAR. Jogadoras de vôlei que nasceram homens superam preconceitos e se estabelecem no esporte. 2017. 09 de abril de 2017. Disponível em < https://globoplay.globo.com/v/5788637/ >. Acesso em 08 out. 2017.

ESPORTE ESPETACULAR. Polêmica na Superliga: primeira atleta transgênero do torneio divide opiniões no esporte. 2018. 14 de janeiro de 2018. Disponível em < https://globoplay.globo.com/v/6421019/ >. Acesso em 16 jan. 2018.

FISCHER, Mia; MCCLEAREN, Jennifer. Transgender Athletes and the Queer Art of Athletic Failure. Communication \& Sport, v. 8, n. 2, p. 147-167, 2020.

HARPER, Joanna. Sport's transgender debate needs compromise not conflict. The Guardian, Orthopedics \& Sports Medicine, 2019. Disponível em: < 
https://www.theguardian.com/sport/blog/2019/apr/01/sports-transgender-debatecompromise-not-conflict >. Acesso em: 29 abr. 2020.

HEMBREE, Wylie C. et al. Endocrine Treatment of Gender-Dysphoric/GenderIncongruent Persons: An Endocrine Society. Clinical Practice Guideline. The Journal of Clinical Endocrinology and Metabolism, v. 102, n. 11, p. 3869-3902, nov. 2017.

IOC. International Olympic Committe. IOC Consensus Meeting on Sex Reassignment and Hyperandrogenism. 2015. Available in: < https://stillmed.olympic.org/Documents/Commissions_PDFfiles/Medical_commission/2 015-11_ioc_consensus_meeting_on_sex_reassignment_and_hyperandrogenism-en.pdf

>. Access in 11 jun. 2019.

JARDIM, Juliana G."It's time"! MMA feminino, mercado da beleza e cisheteronormatividade: uma etnografia multissituada com lutadoras brasileiras. 225f. 2018. Tese (Doutorado em Ciências Sociais). Universidade Estadual Paulista, Marília/SP, 2018.

LE BRETON, David. Corpo, gênero, identidade. Trad. Gercélia Batista de Oliveira Mendes. In: FERRARI, Anderson et al. (Orgs.). Corpo, gênero e sexualidade. Lavras: UFLA, 2014. p. 18-34.

PETRY, Analídia Rodolpho. Mulheres transexuais e o Processo Transexualizador: experiências de sujeição, padecimento e prazer na adequação do corpo. Revista Gaúcha de Enfermagem, v. 36, n. 2, p. 70-75, jun. 2015.

PINK, Sarah et al. Ethnography in a digital world. In: PINK, Sarah et al. Digital ethnography: principles and practice. Los Angeles, Londres, Nova Déli, Singapura e Washington: Sage, 2016. p. 1-18.

PRADO, Vagner Matias do; NOGUEIRA, Alessandra Lo Gullo A. Transexualidade e esporte: o caso Tiffany Abreu em "jogo". REIS - Revista Eletrônica Interações Sociais, v. 2, n.1, p. 60-72, jan./jun. 2018.

PRECIADO, Paul Beatriz. Manifesto Contrassexual: políticas subversivas de identidade sexual. São Paulo: n-1 edições, 2014.

TRIVIÑOS, Augusto Nibaldo S. Introdução à pesquisa em ciências sociais: a pesquisa qualitativa em educação. O positivismo; a fenomenologia; o marxismo. São Paulo: Atlas, 2015.

VERGUEIRO, Viviane (Simakawa). Por inflexões decoloniais de corpos e identidades de gênero inconformes: uma análise autoetnográfica da cisgeneridade como normatividade. 2015. 243f. Dissertação (Mestrado em Cultura e Sociedade). Instituto de Humanidades, Artes e Ciências Professor Milton Santos, Universidade Federal da Bahia, Salvador/BA, 2015. 
Trans resistance in Paranaense female volleyball

\begin{abstract}
This work aimed to problematize the resistance of transsexual women in female volleyball of the State of Paraná, with the guiding questions: 1- how do these athletes build resistance networks to remain in volleyball? 2- which barriers erupt as obstacles along your personal and sports trajectory(ies)? Methodologically, it was developed a qualitative study, with two testimonies from two trans women volleyball players that act in the metropolitan region of Curitiba/PR. The data were treated based on the content analysis technique. The results pointed out the processes of resilience and maintenance in the sports field, constantly surrounded by cisheteronormative elements that, when imposing themselves, silence the trans corporealities. However, the athletes count on the support of their social groups and persist in their trajectory, in the midst of problems that arise during games, outside the courts and in other spheres, such as in the legislature, for example.
\end{abstract}

Keywords: Transgender persons; Women; Sports; Volleyball; Brazil.

\title{
Resistencia trans en el voleibol femenino paranaense
}

Resumen: Este trabajo teve como objetivo problematizar la resistencia de las mujeres transexuales en el voleibol femenino en el Estado del Paraná, con estas preguntas orientadoras: 1- ¿Cómo estas atletas construyen redes de resistencia para permanecer en el voleibol? 2- ¿Qué barreras estallan como obstáculos a lo largo de su trayectoria personal y deportiva? Metodológicamente, desarrollo-se un estudio cualitativo, con dos testimonios de dos jugadoras de voleibol trans que actúan en la región metropolitana de Curitiba/PR. Trataran-se los datos basados en la técnica de análisis de contenido. Los resultados apuntaron a los procesos de resiliencia y mantenimiento en el campo deportivo, constantemente rodeados de elementos cisheteronormativos que, al imponerse, silencian las corporeidades trans. Sin embargo, los atletas cuentan con el apoyo de sus grupos sociales y persisten en su trayectoria, en medio de los percances que surgen tanto durante los juegos, como fuera de las canchas y en otras esferas, como en la legislatura, por ejemplo.

Palabras clave: Personas transgénero; Mujeres; Deportes; Voleibol; Brasil

Recebido: 12/05/2020

Aceito: 31/03/2021 